\title{
Marine systems analysis and modeling
}

\author{
K. Fedra \\ Advanced Computer Applications (ACA), International Institute for Applied Systems \\ Analysis (IIASA); Schlossplatz 1, A-2361 Laxenburg, Austria
}

\begin{abstract}
Oceanography and marine ecology have a considerable history in the use of computers for modeling both physical and ecological processes. With increasing stress on the marine environment due to human activities such as fisheries and numerous forms of pollution, the analysis of marine problems must increasingly and jointly consider physical, ecological and socio-economic aspects in a broader systems framework that transcends more traditional disciplinary boundaries. This often introduces difficult-to-quantify, "soft" elements, such as values and perceptions, into formal analysis. Thus, the problem domain combines a solid foundation in the physical sciences, with strong elements of ecological, socio-economic and political considerations. At the same time, the domain is also characterized by both a very large volume of some data, and an extremely data. poor situation for other variables, as well as a very high degree of uncertainty, partly due to the temporal and spatial heterogeneity of the marine environment. Consequently, marine systems analysis and management require tools that can integrate these diverse aspects into efficient information systems that can support research as well as planning and also policy- and decisionmaking processes. Supporting scientific research, as well as decision-making processes and the diverse groups and actors involved, requires better access and direct understanding of the information basis as well as easy-to-use, but powerful tools for analysis. Advanced information technology provides the tools to design and implement $\mathrm{s} \mathrm{m}$ a r t software where, in a broad sense, the emphasis is on the man-machine interface. Symbolic and analogous, graphical interaction, visual representation of problems, integrated data sources, and built-in domain knowledge can effectively support users of complex and complicated software systems. Integration, interaction, visualization and intelligence are key concepts that are discussed in detail, using an operational software example of a coastal water quality model. The model comprises components of a geographical information and mapping system, data bases, dynamic simulation models, and an integrated expert system. An interactive graphical user interface, dynamic visualization of model results, and a hyper-text-based help-and-explain system illustrate some of the features of new and powerful software tools for marine systems analysis and modeling.
\end{abstract}

\section{INTRODUCTION}

Growing concern about the environment, including oceans, coastal waters and the impacts of human activities, immediate as well as long-term, makes the monitoring of the state of our environment, the prediction and analysis of environmental impacts and risks, and the design of policies and strategies for the management and protection of the environment a task of considerable urgency and global importance. Environmental information systems that include simulation models are a class of powerful, computerbased tools that can support this task, both for scientific research and for planning and policy making.

Modeling of marine systems has a considerable tradition in both physical and biological oceanography. For summary treatments, more recent model comparisons, and 
some classics in the field see, for example, Riley et al. (1949); Nihoul (1975); Goldberg et al. (1977); Kremer \& Nixon (1978); Falconer et al. (1989); Fransz et al. (1991).

However, most of these approaches are designed to improve scientific understanding of physical and biological processes, with the notable exception of some of the fisheries models that have obvious management implications (e.g. Andersen \& Ursin, 1977). Other management-oriented and model-based studies of marine systems include the RAND Corporation classic on the Oosterschelde (Bigelow et al., 1977) or the recent study of the North Sea MANS, Management Analysis North Sea (Anonymous 1988; 1989; Klomp, 1990). Here, as well as in a number of similar projects including models, the emphasis is on environmental and resource management issues, on decision support rather than primarily scientific progress.

Addressing management issues, and placing the physical and ecological phenomena into the broader framework of technological and socio-economic systems also involves different audiences that include specialists from many areas, public officials, and the general public. This implicates different languages and traditions that often make communication difficult. An important feature of information systems is to provide a common information basis, but also a common language for a diverse group of users, which could include, for example, marine biologists, regional planners, sanitary engineers, fisheries managers, public officials, and environmental activists.

\section{ENVIRONMENTAL INFORMATION SYSTEMS}

A large amount of formal, mathematical and computational methods have been developed for environmental applications, including the area of physical and biological oceanography. They range from research-oriented tools that advance our understanding of complex systems and phenomena, to very practical tools for specific management tasks.

Many computer-based models and methods are potentially useful, and not only for their developers. However, to turn a potentially useful method into one actually used by a broader group of users, requires a number of special features as well as an approach that takes psychological and institutional aspects as well as scientific and technical ones into account. This, in particular, is important in the area of environmental impact assessment, planning and management, where physical and engineering considerations need to be combined with ecological and ultimately socio-economic aspects for an integrated assessment, ultimately, the support of decision-making processes.

The availability of affordable computers, as well as new technologies such as expert systems, geographical information systems, or dynamic computer graphics, now make it possible for powerful, accessible, and easy-to-use information and decision support systems for environmental research, planning, management, and impact assessment to be built (Fedra \& Loucks, 1985; Loucks \& Fedra, 1987). These systems are designed to provide scientists, planners and policy makers with direct and interactive access to a large volume of information in combination with methods of scientific analysis.

Basic components of these environmental software systems include:

- Geographical Information Systems that provide access to spatial marine data, such as monitoring data, bathymetry, but also to spatial data on coastal regions' land use, 
infrastructure, resources, site-specific information (e.g. cities, waste-water treatment plants) as well as providing tools for spatial analysis;

- Data Bases, containing non-spatial data such as eco-physiological data on individual species, or parameters of hazardous chemicals;

- Knowledge Bases, representing qualitative (symbolic) knowledge about the problem domain, that allow logical deductions to be made;

- Simulation and Optimization Models, representing process-oriented numerical and algorithmic assessment tools;

- Graphical User Interface, integrating the above into one coherent system and providing the user with interactive access and a high degree of dynamic visualization.

Computer based tools that are easy to use, equipped with a friendly user interface, use problem-adequate representation formats and a high degree of visualization, customized for an institution and its specific view of problems, and that are developed in close collaboration with the end user, stand a better chance of being used than tools that are based on "only" good science. Good science is a necessary, but certainly not a sufficient condition for a useful and usable environmental information and decision support system.

Advanced information technology provides the tools to design and implement $\mathrm{s} \mathrm{m}$ a r t software where, in a broad sense, the emphasis is on the man-machine interface (Fedra, 1991). Integration, interaction and visualization are three key concepts in environmental information systems (Fedra, 1990).

Integration implies that in any given software system for real-world applications, more than one problem representation form or model, several sources of information or data bases, and a multi-faceted, problem-oriented user interface ought to be combined within a common framework to provide a useful and realistic information base. Integration also means that tools such as expert systems components can be embedded in, for example, simulation models and user interfaces in general, providing the means for smart systems behaviour. The increasing complexity of such composite tools, in turn, requires a well-structured and modular approach, supported by technological developments such as powerful workstations supporting bit-mapped colour graphics and cost-effective highvolume mass storage, distributed computing and networking support, or object-oriented software.

Interaction is a central feature of any effective man-machine system: a real-time dialogue allows the user to define and explore a problem incrementally in response to immediate answers from the system; fast and powerful systems with modern processor technology can offer the possibility to simulate dynamic processes with animated output, and they can provide a high degree of responsiveness that is essential for maintaining a successful dialogue and direct control over the software. Obviously, raw computer power, but also the availability of appropriate input and output devices, such as high-resolution colour screens or mouse pointers, are key requirements here.

Visualization provides the bandwidth necessary to understand large amounts of highly structured information, and permits the development of an intuitive understanding of processes and interdependencies, of spatial and temporal patterns, and complex systems in general (Fedra, 1990). Many of the problem components in a real-world planning or management situation are rather abstract; representing them in a symbolic, graphical format that allows visual inspection of systems behaviour, and, in general, symbolic interaction with the machine and its software, is an important element in friendly and easy-to-use computer-based systems. 


\section{An application example}

To illustrate the ideas introduced above, an application to coastal water quality modeling is presented. The system was developed by IIASA's Advanced Computer Applications Project, in collaboration with Delft Hydraulics, who contributed the basic numerical models. The system was implemented for a number of locations in the Irish Sea, with a case study of Swansea Bay. The Swansea Bay area is heavily industrialized, leading to water quality problems not only from domestic wastewater and sludge with organic material, BOD, and coliform bacteria, but also from several industrial sources containing heavy metals (Collins et al., 1980). As such, it is representative of numerous similar coastal areas suffering from various levels of pollution all over the world.

Recent applications of simulation models in this field include, for example, Lewis \& Riddle (1989) and Krohn et al. (1991). Mates \& Scheinberg (1991) discuss a model with emphasis on recreational activities, and Barnes (1988) looks at non-point sources and a cartographic approach. A food chain model for PCB accumulation is presented by Connolly (1991), and Reed et al. (1989) discuss a complex model system, namely the Natural Resource Damage Assessment Model System for Coastal and Marine Environments that is primarily oriented towards accidental spills. Economic aspects in the case of effluent charges and chlorine residuals from the forest industry polluting the Baltic Sea are considered by Hultkrantz (1991).

The model system for Swansea Bay simulates the fate and distribution of various types of pollutants, such as conservative tracers, BOD, or coliform bacteria from one or several outfalls or off-shore dumping locations. The system includes:

- a data base of these major sources of pollution, e.g. wastewater treatment plants and outfall pipelines, linked to

- a geographical information system (GIS) component that can manage spatial data, such as land-use information or bathymetry, as well as observational data, such as flows, tidal records, or water quality measurements;

- an interactive and graphical interface to model scenario editors as well as for running the models visualizing the dynamic model output;

- coupled to the scenario editors, an embedded expert system for scenario editing and parameter estimation; and as a post-processor of model results, an expert system for impact assessment;

- coupled with the expert system's rule base as well as the editor functions and the overall help and explain functions, a hypertext system for additional textual information.

The basic modules of the system are shown in Figure 1.

\section{The simulation models}

The Coastal Water Quality Modeling System is a generic framework that can accommodate one or several 2D dynamic hydrodynamic and water quality models. The current version combines the TRISULA-2D hydrodynamic model, used as an off-line preprocessor to generate hydrodynamic scenarios, with the dynamic water quality models DELPAR-2D for the near-field and DELWAQ-2D for the far-field. All models were developed by Delft Hydraulics (Delft Hydraulics, 1990). 


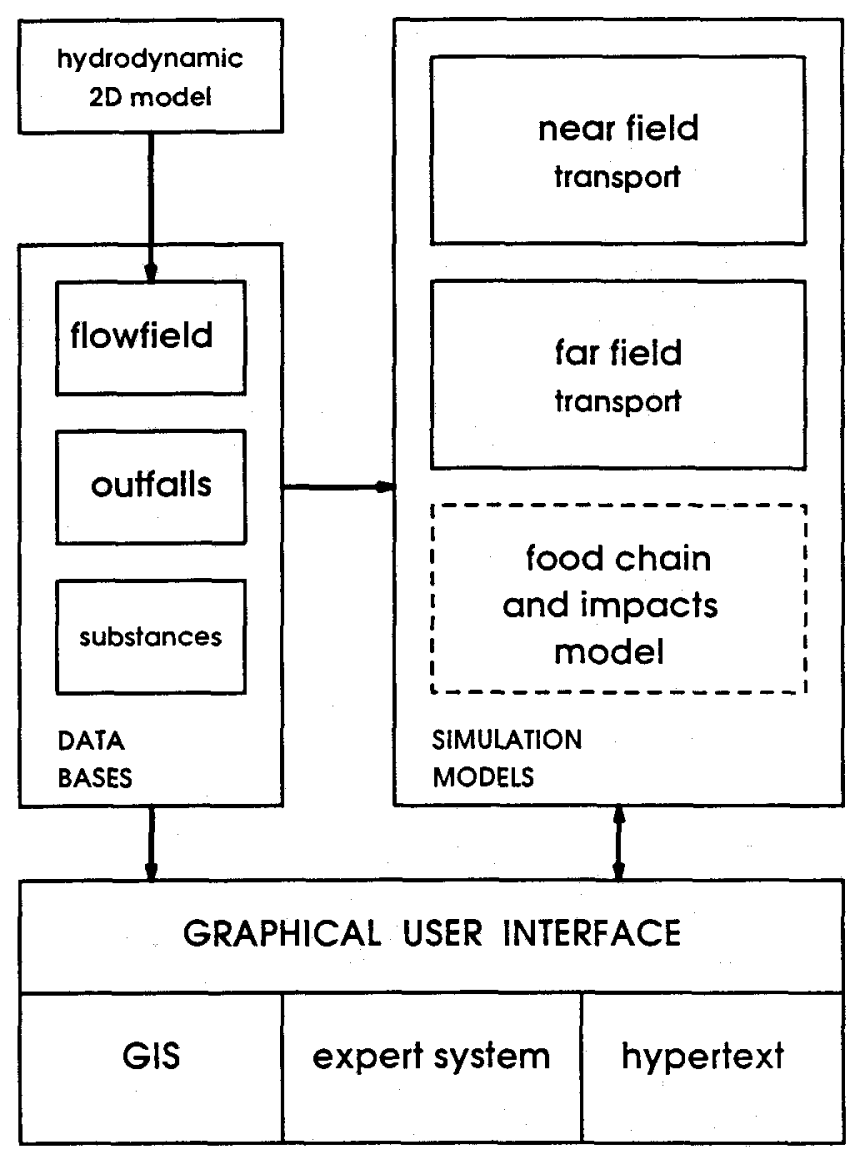

Fig. 1. The major components of the software system

For the purpose of modeling both near-field and far-field dispersion resulting from the continuous release of more or less persistent substances, a particle-tracking model (DELPAR) and a general finite difference water quality model (DELWAQ) were coupled. The finite difference model uses the same grid as the hydrodynamic model, and uses the flowfield generated by the hydrodynamic model (Fig. 2). For the initial, subgrid stage of dispersion in the vicinity of pollution sources (outfalls), a particle-tracking model was implemented. This particle-tracking model enables high sub-grid resolution and incorporates important phenomena for near-field dispersion explicitly, like vertical velocity gradients and wind effects.

The particle-tracking model assumes that concentrations can be seen as a number of mass particles per volume. The mass particles are considered to be subject to Brownian movement and small-scale turbulences, but also to horizontal transport by the current. The model computes the expected location of each of several thousands of particles and derives concentration values (contours) from their locations.

The model assumes a horizontal random displacement step that is consistent with the 


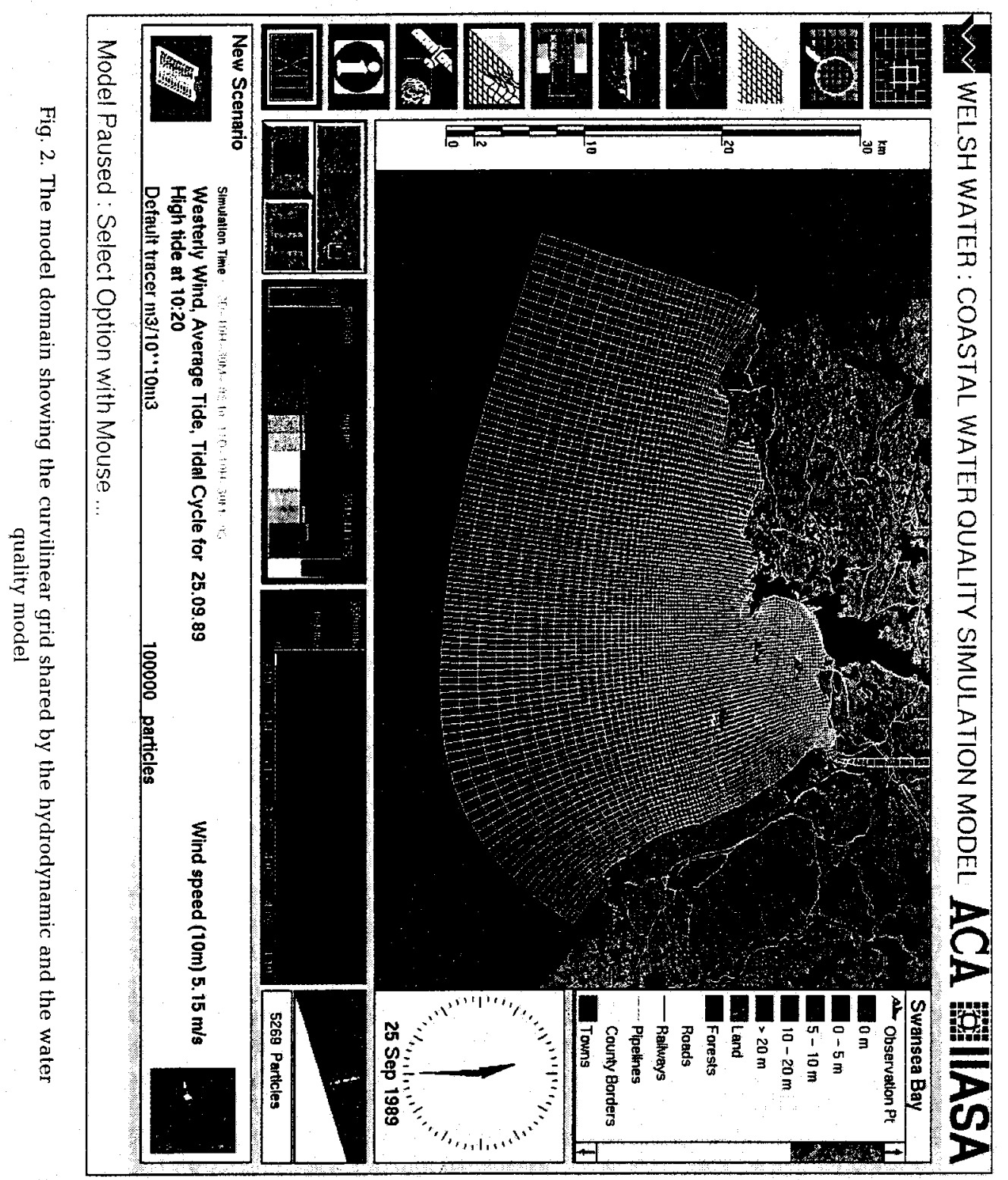


dispersion coefficient approach used for other models. For this reason, the user is required to provide the model with the parameters of a diffusion formula of the type $D=$ $a t^{b}$.

From basic calculus and stochastic limit theorems it can be shown that the random step size is proportional to the square root of $D \cdot \Delta t$, where $D$ is the diffusion coefficient and $\Delta t$ is the time step of the simulation.

Both water quality models and their calibration for a case study of Swansea Bay are described in Delft Hydraulics (1990).

\section{Integration and user interfaces}

A complex suite of models, like the hydrodynamic model and the two water quality models, are powerful and sophisticated tools that require substantial user expertise for the preparation of input data files, running of the actual code, and the post-processing and interpretation of the very large amount of numerical results generated even by a single model run.

Building them into a problem-oriented framework, with a user-friendly interface, allows a more experimental use of the model. A user can concentrate on the analysis, on the comparative evaluation of alternatives, both in terms of the design and decision variables such as outfall locations and characteristics, or model parameters. Patterns and trends over time, in space, but also in the relationship of driving variables and systems responses can be identified in this interactive and graphical approach.

The dynamic and visual representation of model results allows the user to develop an intuitive understanding of complex, spatially distributed and dynamic systems behaviour. The visualization is not only helpful in communicating with a non-technical audience: the high bandwidth of the dynamic graphics enables a user to scan a very large amount of information that would be clearly incomprehensible in a numerical, i.e. tabular, format. Also, many behavioural features of a model, and even errors, may only become obvious through the use of a multitude of representation forms and display styles.

In the Wales model, the primary display style is constrained by the two dimensional nature of the model: concentration fields are plotted over a map of the area (Fig. 3). As added features, both the model grid and the flow field (represented by small vectors indicating magnitude and direction of flow) can be displayed. Different colour choices, and the ability to interactively tune the graphical interpretation of the numbers generated, i.e. stretch the contrast along a user-defined range of the concentration frequency distribution, allow a broad range of display options. Zooming into the map provides higher resolution for sub-areas (Fig. 4).

In addition to the animated concentration field, the user can define observation points and generate graphs of concentration over time for these locations.

Finally, the concentration field can also be displayed in a pseudo 3D graph, where the functional value over each grid cell is displayed in the vertical (Fig. 5).

The dynamic model allows the user to simulate specific scenarios, i.e. sets of design variables and assumptions for model parameters and inputs. A primary design variable is the location and nature of the outfalls simulated. Another choice is that of the substance simulated, e.g. a conservative tracer, BOD, or coliform bacteria.

Another choice is the selection of a hydrodynamic scenario, representing at least one 


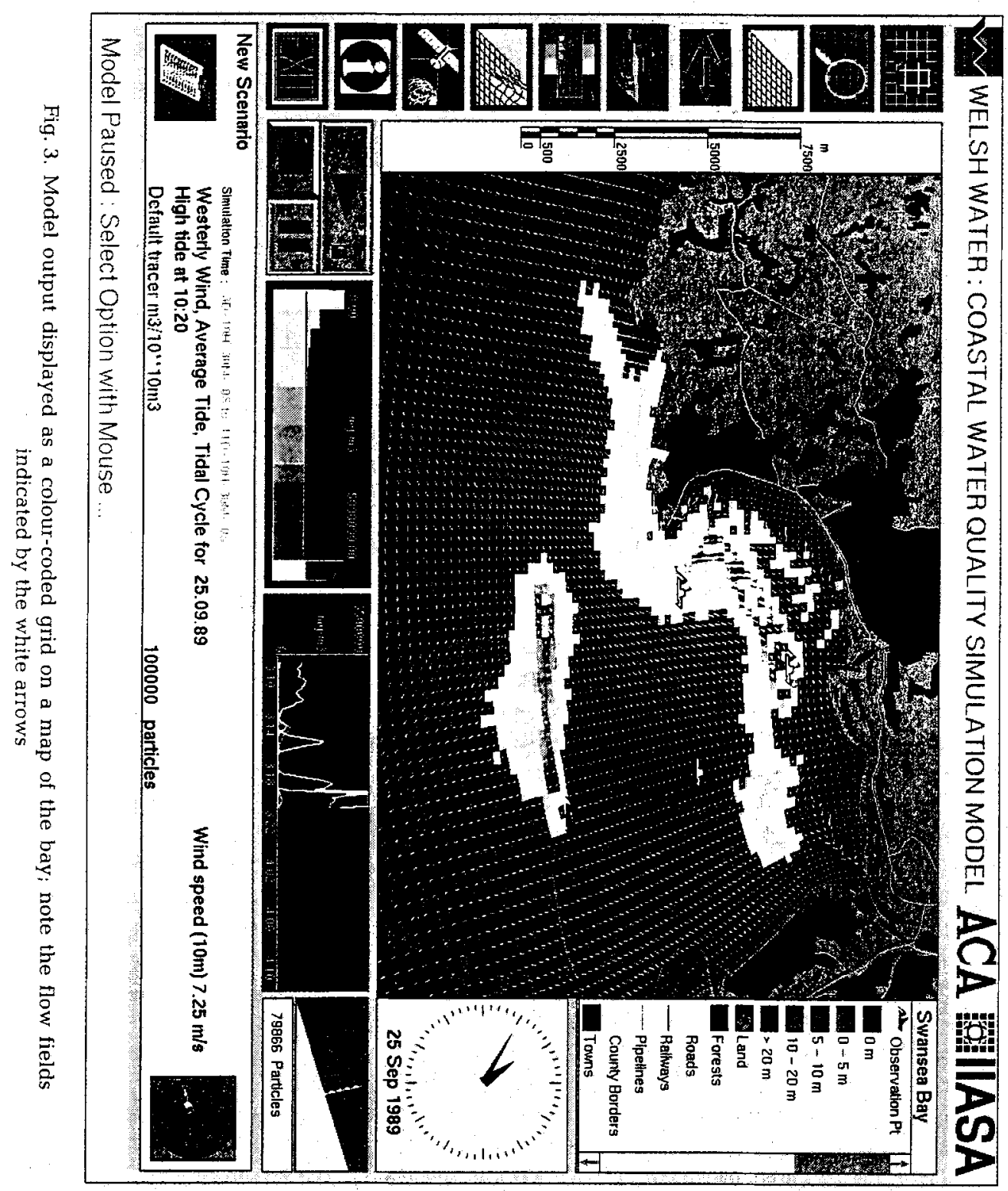




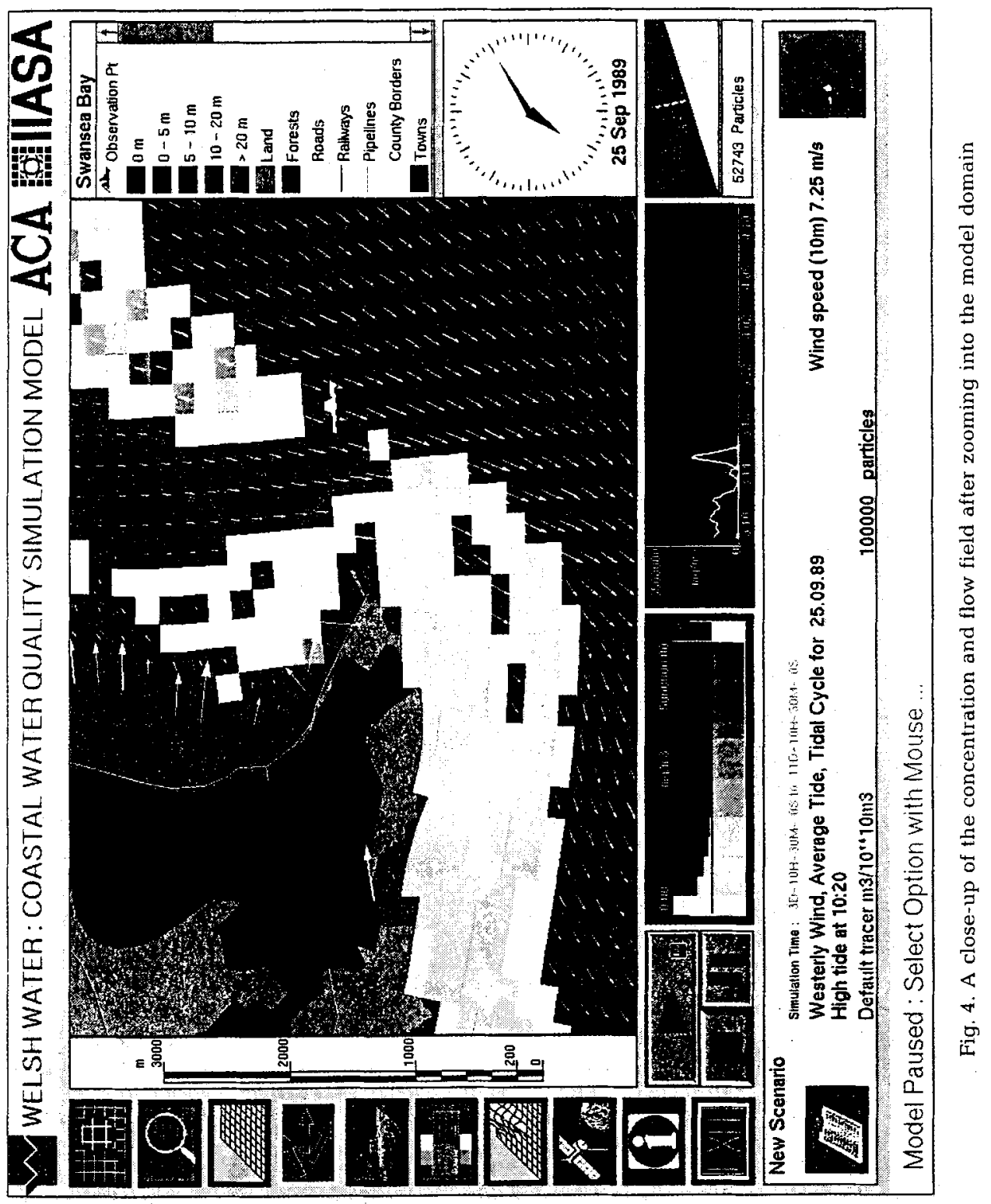




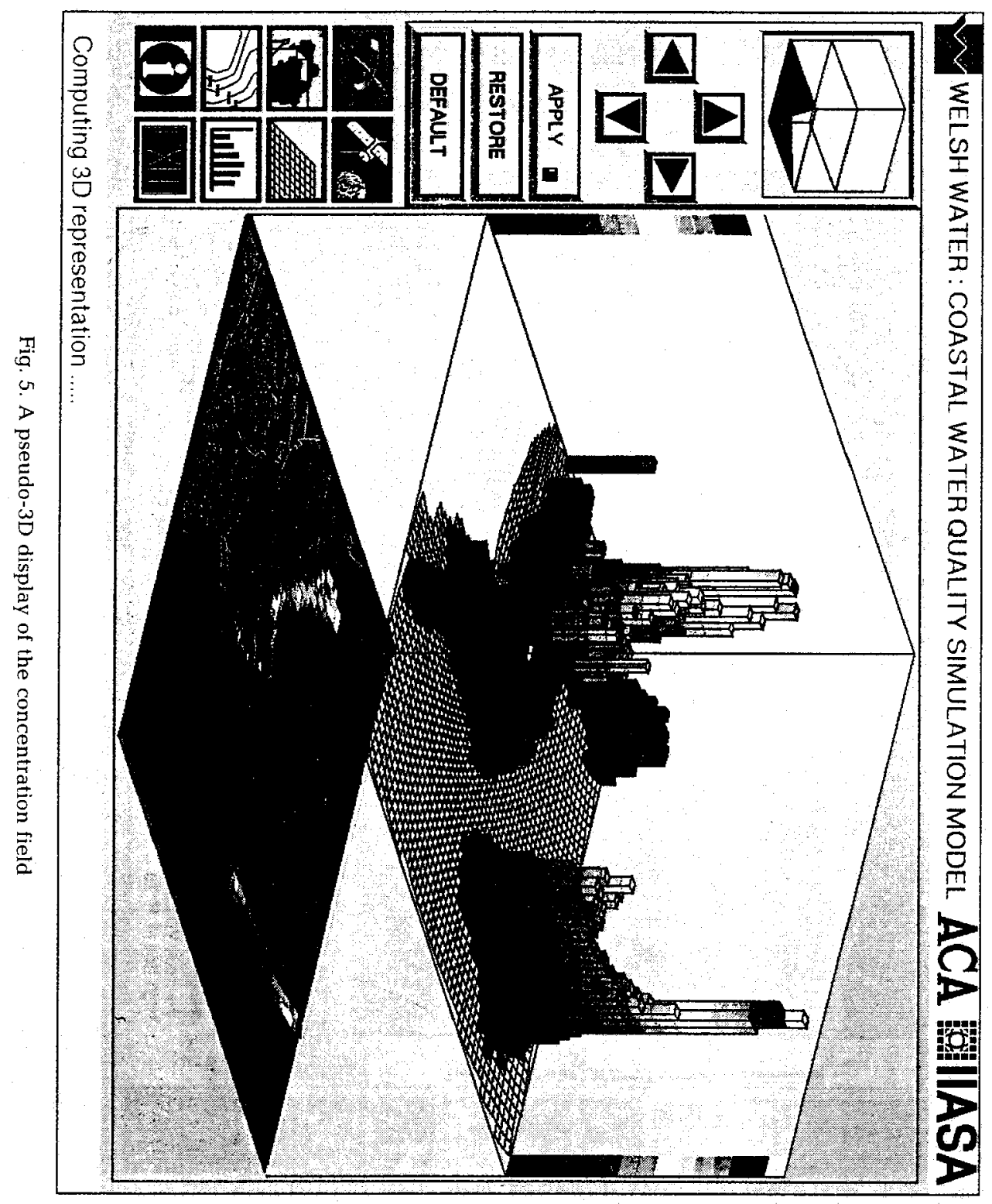




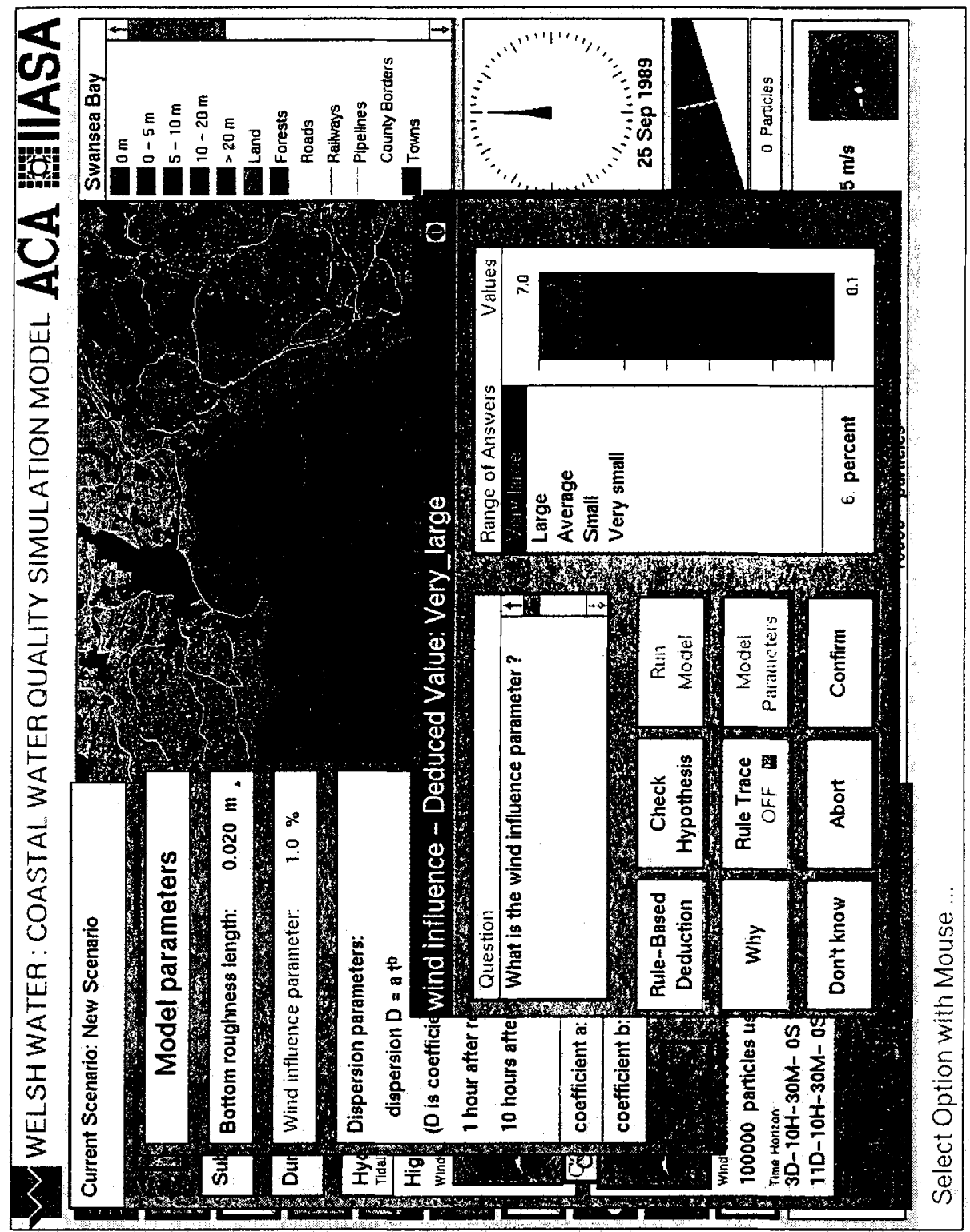

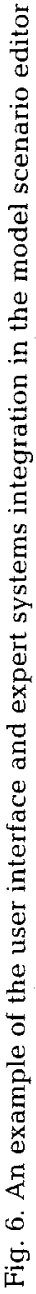


full tidal cycle. The hydrodynamic scenarios are precomputed with a two dimensional, vertically averaged hydrodynamic simulation model TRISULA 2D (Delft Hydraulics, 1990). The user can also set a prevailing wind direction and wind speed that will influence the precomputed flow fields. Finally, the user can choose the number of particles to be used in the particle model, which allows an optimal choice between "precision" or smoothness of the results and the speed of the model.

At a second level, the "expert" level of the user interface, additional model parameters can be modified. At the normal user interface level, default values are used. To calibrate the model, however, a modification of model parameters such as the wind influence parameter, bottom roughness length, or the coefficients used to represent diffusion as a function of time in the particle tracking approach (Fig. 6).

At this level, a rule-based expert system helps to set these parameters, for example, when calibrating the model against observation data. The expert system used, its syntax and functionality, as well as an application example in water resources planning and environmental impact assessment are described in Fedra et al. (1991). The rules of the system represent the experience of one or several modelers intimately familiar with the code and its behaviour, but also the nature of the location, or specific elements in the systems behaviour. For example, observed deviations of peak value or the spread of the pollutant, deviations related to the wind direction, etc., can be used to guide the user in adjusting the respective parameters.

\section{From simulation to decision support}

The basic mode of operation of the system is scenario analysis. However, to turn the system into a useful tool for the evaluation of alternative outfall scenarios in terms of their environmental consequences, the user must be provided with additional information and, in particular, with economic and policy-related criteria (Fedra, 1985). These must include, for the outfall scenario, the cost of a given scheme in terms of investment, operations, maintenance, and replacement costs. At least a first approximation of the costs for a treatment plant can be estimated from, for example, the population served, the amount of trade waste, the level of treatment, and the location (distance from the plant) of the outfall.

The environmental impact, on the other hand, can be described, for example, in terms of the area above a given water quality standard, the degree and duration of the violation, or the average concentration over time in a given sensitive area such as the immediate shoreline.

These additional descriptors or criteria for a given hydrodynamic reference scenario or a range of typical hydrodynamic scenarios provide the basis for a multi-criteria evaluation of cost criteria versus environmental impacts and compliance with standards and regulations (Fig. 7).

The same embedded expert system used for parameter estimation and the consistent definition of scenarios can also be used in the interpretation of the model results, for example to assess compliance with water quality standards. Compliance with standards can conveniently be expressed as a rule of the following equation:

IF pollutant concentration is above standard

THEN water quality standard is violated 


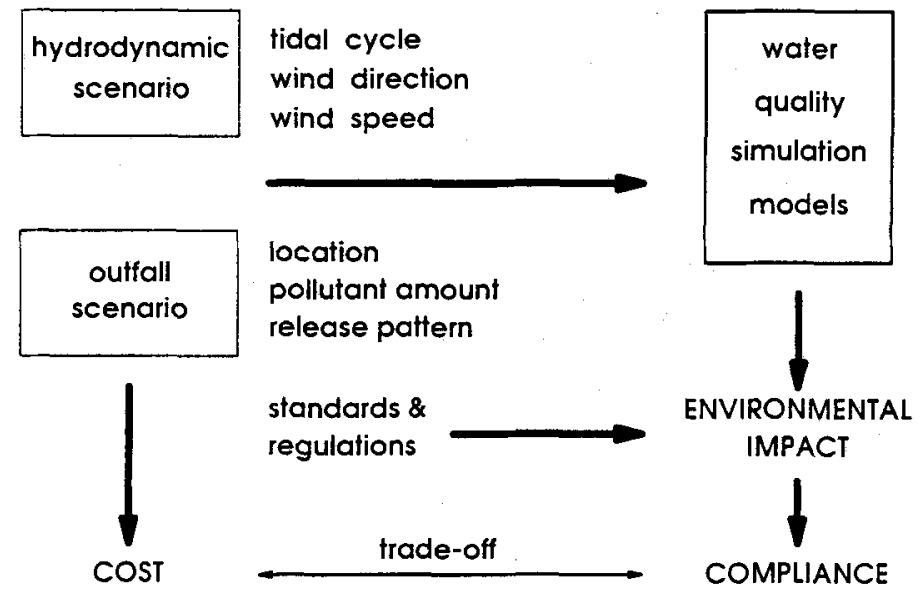

Fig. 7. A framework for scenario analysis: from simulation to decision support

The rule-based expert system can also use perceptions of water quality (in terms of colour, foam, algae on the beach, smell, etc.) to generate additional, qualitative criteria for the assessment of a scenario. Finally, the expert system can be used to perform a more complex and comprehensive impact assessment at the chosen screening level, based on the computed pollutant concentrations (Fedra et al., 1991).

\section{DISCUSSION}

Built around one or more coupled models, numerical simulation models or ruledriven inference models, the above example features:

- an interactive, menu-driven user interface that guides the user with prompt and explanatory messages through the application. The computer assists the user in its proper use; no computer experience is required to use this tool;

- dynamic colour graphics for the model output and a symbolic representation of major problem components that allow easy and immediate understanding of basic patterns and relationships. Rather than emphasizing the numerical results, symbolic representations and the visualization of complex patterns, in time and space, support an intuitive understanding of the behaviour of complex systems;

- the coupling with one or several data bases that provide the models with necessary input information. The user's choice or definition of a specific scenario can be expressed in an aggregated and symbolic, problem-oriented manner, without concern for the technical details of the computer implementation;

- embedded AI components, such as specific knowledge bases, allow user specitications in allowable ranges to be checked and constrained, thus ensuring the consistency of an interactively defined scenario.

In summary, the software system is designed for easy and efficient use, even in datapoor situations, and caters to the user's degree of expertise. The "intelligent" interface and its pre- and post-processing functions free the user from the time-consuming and 
error-prone tasks of data file preparation, the routine of model runs, and finally from the interpretation and translation of numerical results into meaningful terms that are adequate to the problem. This not only allows the user to employ the models more freely in an experimental and interesting way, it also allows the analyst to concentrate on the more important tasks they can do best, i.e. the recognition of emerging patterns, the comparative evaluation of complex alternatives, and the entire institutional aspects of any environmental impact assessment rather than its technicalities.

It is, however, important to recognize that there is a price to be paid for the ease of use of such systems: not only are they more expensive to build - after all, the information that makes them smart has to be compiled and included at some stage - they are also much less flexible than their more conventional, general-purpose siblings. Only by restricting the range of applications can more application-specific knowledge be built into the systems and thus make them appear smart. There is no such thing as the generalpurpose problem solver, or a generic model or decision support system that is easy to use. Mastery of a problem area comes only at the price of narrow specialization.

Nevertheless, or maybe just because of these restrictions, the above examples illustrate that computer-based methods can be powerful tools to support marine systems analysis and modeling. However, it is important to realize what their actual role and limitations are.

Certainly the expert systems approach, or any computerized decision support system for that matter, is not a replacement for the human expert in such a complex problem domain; it still requires a knowledgeable and responsible person to use it, to interpret and apply the results, whether for research purposes or in the environmental planning and decision-making process. However, the system will take care of the more mundane tasks of data handling, freeing the analyst to concentrate on the real problems that require human creativity, which is somewhat difficult to build into computers.

Information and decision-support systems, whether they are expert systems or based on simulation or optimization models, organize the planning or decision-making process; they provide structure, ensure completeness, and may even ascertain plausibility. It is the easy-to-use "smart" interface, the fast and efficient operation, and the apparent intelligence of the programs that makes them attractive. Based on the organized collection of experience of numerous experts, international literature, but also on various guidelines, regulations, and environmental law, a systems knowledge base, with or without one or more numerical models in its core, may indeed offer intelligent advice to any individual user.

The same holds true for the simulation models: by integrating data bases, GIS components, and embedded AI technology, they are easy and efficient to use. They allow the analyst to test numerous assumptions, run multiple scenarios under varying assumptions, and to explore the problem. Similar ideas of identifying and comparing several alternative models for marine pelagic foodwebs were presented more than ten years ago (Fedra, 1981); what was then a nice idea is technical reality now.

The models certainly will not be able to predict the future state of the environment with a high degree of precision; but they can reveal patterns and trends, and hopefully they will make the analyst think. The precision of results in any modeling approach, and in particular when predicting expected environmental impacts of projects that are, at this stage, only on the drawing board and thus do not allow for any measurements in the field, 
has obvious limitations. However, forecasting results must include the uncertainty of the estimate as part of the information provided, as an important aspect for their further use, i.e. decision making.

The interactive approach, the integration of the models with the necessary data bases, and the visualization of results in formats that are intuitively understandable make them attractive tools. By relying on symbolic representation and a menu-driven user dialogue that uses the machine not only to perform the necessary information processing tasks but at the same time to guide and assist the user in his analysis and assessment, the approach becomes sufficiently general to be useful in a wide range of institutional circumstances and application areas.

\section{LITERATURE CITED}

Andersen, K. P. \& Ursin, E., 1977. A multispecies extension to the Beverton and Holt theory of fishing, with accounts of phosphorus circulation and primary production. - Meddr Danm. Fisk.og Havunders. 7, 319-435.

Anonymous, 1988. MANS - Management analysis North Sea. Summary report 1987. Rijkswaterstaat, North Sea Directorate, The Hague, $39 \mathrm{pp}$.

Anonymous, 1989. Modelling of the North Sea water quality. Rijkswaterstaat, Tidal Waters Division, The Hague, $24 \mathrm{pp}$.

Barnes, K. B., 1988. Cartographic modeling of nonpoint pollutant surfaces for a coastal drainage area. In: Proceedings of the Symposium on Coastal Water Resources. Ed. by K. B. Barnes, W. L. Lyke \& T. J. Hoban. American Water Resources Association, Bethesda, 133-146.

Bigelow, J. H., Haven, J. C. de, Dzitzer, C., Eilers, P. \& Peeters, J. C. H., 1977. Protecting an estuary from floods - a policy analysis of the Oosterschelde. III.: Assessment of long-run ecological balances. Rand Corporation, Santa Monica. 215 pp. (R-2121/4-NETH).

Collins, M. B., Banner, F. T. \& Tyler, P. A. (Eds), 1980. Industrial embayments and their environmental problems. A case study of Swansea Bay. Pergamon Press, Oxford, 608 pp.

Connolly, J. P., 1991. Application of a food chain model to polychlorinated biphenyl contamination of the lobster and winter flounder food chains in New Bedford Harbor. - Environ. Sci. Technol. 25, $760-770$

Delft Hydraulics (Ed.), 1990. Draft - Swansea Bay Model - dispersion modelling and particles tracking model (T647). Delft Hydraulics, Delft, 78 pp.

Falconer, R. A., Goodwin, P. \& Matthew, R. G. S. (Eds), 1989. Hydraulic and environmental modeling of coastal, estuarine and river waters. Proceedings of the International Conference held at the University of Bradford, 19-21 September 1989. Gower Technical, Aldershot, $694 \mathrm{pp}$.

Fedra, K., 1981. Pelagic foodweb analysis: hypothesis testing by simulation. - Kieler Meeresforsch. (Sonderh.) 5, 249-258.

Fedra, K., 1985. A modular interactive simulation system for eutrophication and regional development. - Water Resour. Res, 21 (2), 143-152.

Fedra, K., 1990. Interactive environmental software: integration, simulation and visualization. In: Informatik für den Umweltschutz. Proceedings of the 5th Symposium on Computer Science for Environmental Protection, 19-21 September 1990, Vienna, Austria. Hrsg. von W. Pillmann \& A. Jaeschke. Springer, Berlin, 733-744.

Fedra, K., 1991. Smart software for water resources planning and management. Decision Support Systems. Ed. by D. P. Loucks \& J. R. da Costa. Springer, Berlin, 145-172. (NATO ASI Ser. [G] 26).

Fedra, K. \& Loucks, D. P., 1985. Interactive computer technology for planning and policy modeling. Water Resour. Res. 21 (2), 114-122.

Fedra, K., Winkelbauer, L. \& Pantulu., V. R., 1991. Expert systems for environmental screening. An application in the lower Mekong Basin. RR-91-19. International Institute for Applied Systems Analysis, Laxenburg, 169 pp.

Fransz, H. G., Mommaerts, J. P. \& Radach, G., 1991. Ecological modelling of the North Sea. - Neth. J. Sea Res. $28(1 / 2), 67-140$. 
Goldberg, E. D., McCave, I. N., O'Brien, J. J. \& Steele, J. H. (Eds), 1977. The sea. Vol. 6: Marine modeling. Wiley, New York, $1048 \mathrm{pp}$.

Hultkrantz, L., 1991. The cost of edible fish - effects on the Swedish and Finnish forest industries from the imposition of effluent charges on chlorine residuals in Sweden. - J, environ. Mgmt 32, 145-164.

Klomp, R., 1990. Modelling the transport and fate of toxics in the southern North Sea. - Sci. total Environment. 97/98, 103-114.

Kremer, J. N. \& Nixon, S. W., 1978. A coastal marine ecosystem - simulation and analysis. Springer, Berlin, $217 \mathrm{pp}$.

Krohn, J., Müller, A. \& Puls, W., 1991. Pollutant transport monitoring and prediction by mathematical modelling: North Sea and adjacent estuaries.- Mar. Pollut. Bull. 23, 699-702.

Lewis, R. E. \& Riddle, A. M., 1989. Sea disposal: modelling studies of waste field dilution. - Mar. Pollut. Bull. 20(3), 124-129.

Loucks, D. P. \& Fedra, K., 1987. Impact of changing computer technology on hydrologic and water resource modeling. - Rev. Geophys. 25(2), 107-112.

Mates, A. \& Scheinberg, Y., 1991. A model for approving and controlling sea water pollution for recreational activity. - Toxicol environ. Chem. 31/32, 479-487.

Nihoul, J. C. J. (Ed.), 1975. Modelling of marine systems. Elsevier, Amsterdam, 272 pp.

Reed, M., French, D., Grigalunas, T. \& Opaluch, J., 1989. Overview of a natural resource damage assessment model system for coastal and marine environments. - Oil chem. Pollut. 5, 85-97.

Riley, G. A., Stommel, H. \& Bumpus, D. F., 1949. Quantitative ecology of the plankton of the western North Atlantic. - Bull. Bingham oceanogr. Coll. 12, 1-169. 